\author{
Apr/2018 \\ Working Paper 18-17 \\ rcea.org/RePEc/pdf/wp18-17.pdf
}

\title{
IDENTIFICATION OF COMMON FACTORS IN Panel Data Growth Model
}

\author{
Pinar Deniz \\ Marmara University, Turkey \\ Thanasis Stengos \\ University of Guelph, Canada \\ RCEA \\ M. Ege Yazgan \\ Istanbul Bilgi University, Turkey \\ RCEA
}

Copyright belongs to the author. Short sections of the text, not exceeding three paragraphs, can be used provided proper acknowledgement is given.

The Rimini Centre for Economic Analysis (RCEA) was established in March 2007. RCEA is a private, nonprofit organization dedicated to independent research in Applied and Theoretical Economics and related fields. RCEA organizes seminars and workshops, sponsors a general interest journal, the Review of Economic Analysis (REA), and organizes a biennial conference, the Rimini Conference in Economics and Finance (RCEF). Scientific work contributed by the RCEA Scholars is published in the RCEA Working Paper series.

The views expressed in this paper are those of the authors. No responsibility for them should be attributed to the Rimini Centre for Economic Analysis. 


\title{
Identification of Common Factors in Panel Data Growth Model
}

\author{
Pinar Deniz ${ }^{*}$ Thanasis Stengos ${ }^{\dagger}$ M. Ege Yazgan ${ }^{\ddagger}$
}

April 9, 2018

\begin{abstract}
Cross sectional dependence may lead to inconsistent and inefficient estimators and as such misleading inferences when standard panel data techniques such as fixed/random effects are employed. Pesaran (2006) suggests incorporating cross sectional averages in panel data models as approximates of unobserved common factor(s) to deal with cross sectional dependence. In the context of a standard panel growth model we investigate whether these unobserved common factors can be identified and we find that institutional variables and life expectancy are able to adequately identify them.
\end{abstract}

Keywords: Growth Model, Panel Data, Common Factor, Principal Component Analysis

JEL classification: C23, C38, O43, O47

\section{Introduction}

The empirical literature on the determinants of economic growth has been one of the most active areas of research in the last thirty years. The main benchmark model that has been at the center of all empirical work in the area is based on

*Department of Economics, Marmara University, E-mail: pinar.deniz@marmara.edu.tr

${ }^{\dagger}$ Department of Economics, University of Guelph, E-mail: tstengos@uoguelph.ca

$\ddagger$ Department of Economics, Istanbul Bilgi University, E-mail: ege.yazgan@bilgi.edu.tr 
Solow (1956) and its variants, such as Mankiw et al. (1992) who included human capital in the analysis. The early literature growth empirics relied mainly on cross country data, whereas following Islam (1995) the focus shifted to panel data, which allowed for the presence of country specific effects.

Within the context of empirical growth models that rely on the use of panel data, the most rudimentary approach based on pooled OLS regressions is criticised for disregarding heterogeneities and correlations between cross sectional units. Omitting individual effects, when actually present, renders pooled OLS biased and inconsistent. Fixed/random effect models are used as a solution to this problem. However, the other challenge due to the correlation between cross sectional units may still exist and complicate the analysis. Conventional methods such as fixed/random effects may lead to misleading inference and even inconsistencies in the presence of cross sectional dependence (Phillips and Sul (2003)). Another frequently used panel method, the generalized method of moments (GMM), is also based on the assumption that the error terms are independently distributed across cross sectional units, hence, correlated errors may lead to biased and inconsistent estimators (Sarafidis and Robertson (2009)). De Hoyos and Sarafidis (2006) state that cross sectional dependence may emerge due to unobserved common factors and in the presence of common shocks. Pesaran (2006) proposes common correlated effects (CCE) estimators, in which unobserved common factors are approximated by cross section averages. The technique helps to eliminate correlation among cross sectional units within the residuals in the panel and provides consistent estimates of coefficients. However, the technique does not directly identify the common factors.

In this paper we introduce into the analysis the possible role that institutions may play in explaining these unknown common factors. Our main goal is to establish the link between cross sectional dependence and institutional quality. In fact, in our empirical application we are able to establish that unobserved common factors and institutional variables are observationally equivalent in removing the cross sectional dependence problem. The impact of institutions on economic growth has been extensively examined in the literature. It is argued that better governmental/institutional structures, alleviating the burden on business conditions, contribute to growth (Barro (1996); Dawson (1998); Bassanini 
and Scarpetta (2001); Aisen and Veiga (2013); Easterly et al. (2006); Esfahani and Ramirez (2003)). Barro (2013) highlights the importance of institutions and places them among the most important determinants of cross country differences in long run economic growth and living standards. He argues that the mechanism on executive powers as higher levels of democracy encourage economic activity by checking the power of governments and enhancing property rights. More recently, Nawaz (2015) examines the impact of various institutions on economic growth in a panel dataset for 56 countries over the period 1981-2010 employing fixed effects model and dynamic panel using system GMM and finds that institutions contribute to economic growth.

Pesaran and Tosetti (2011) suggest applying principal component analysis to the residuals of CCE regressions to estimate common factors and their loadings. Following their suggestion, we estimate the common factors by retrieving the principal components of the residuals of a basic panel growth model. We check the correlations between these common factors and some relevant variables. Our empirical results show that the common factors obtained are identified by three institutional indicators ${ }^{1}$, namely as, voice and accountability (VA), political stability and absence of violence (PS), plus life expectancy (LE), which has also been considered as an important growth determinant that is linked to health, human capital and institutional development. Higher LE lengthens working age and increases human capital which further leads to a rise in economic growth (Barro and Salai Martin (1995); Lorentzen et al. (2008)) $)^{2}$. Our empirical analysis implies that using averages of cross sectional units as approximations to unobserved common factors and institutional variables are observationally equivalent in removing the cross sectional dependence problem.

The rest of the paper is organized as follows. Section 2 gives a detailed description of the econometric methodology, while Section 3 discusses empirical findings. The appendix presents details about the data and a table with some additional empirical findings.

\footnotetext{
${ }^{1}$ These variables are individual governance indicators from Kaufmann et al. (2011).

${ }^{2}$ There are also several papers observing a nonlinear relationship where the negativity result due to the impact of mortality reductions on population growth or families' decision on leaving bequests to their children rather than spending on their education (Kelley and Schmidt (1995); An and Jeon (2006); Kunze (2014)).
} 


\section{Econometric Methodology}

Consider the following panel growth regression with cross section units (countries) as $i$ and time units as $t$ where $i=1,2, \ldots, N$ and $t=1,2, \ldots T$,

$$
y_{i, t}=\alpha_{i}^{\prime} \mathbf{d}_{t}+\beta_{i}^{\prime} \mathbf{x}_{i, t}+e_{i, t}
$$

Where $y_{i, t}$ refers to the per capita income growth and $\mathbf{d}_{t}^{\prime}$ represents the vector of observed common factors (common to all countries). ${ }^{3} \mathbf{x}_{i, t}$ is the $k \times 1$ vector of individual specific regressors on the ith cross-section unit at time t. In line with the standard economic growth model $\mathbf{x}_{i, t}$ is assumed to contain three variables $(k=3)$ capturing the contribution of population growth, physical and human capital. $\alpha_{i}$ and $\beta_{i}$ are regression coefficients where the parameters are allowed to vary over $i$ s to take into account cross country heterogeneity in the growth regression.

In the presence of cross sectional dependency, the error terms are assumed to have the following multi-factor structure.

$$
e_{i, t}=\gamma_{i}^{\prime} \mathbf{f}_{t}+\varepsilon_{i, t}
$$

where $\mathbf{f}_{t}=\left(f_{1 t}, \ldots, f_{m t}\right)^{\prime}$ is a m-dimensional vector of unobservable common factors (common to all countries), $\gamma_{i}^{\prime}$ is the associated $m \times 1$ vector of loadings and $\varepsilon_{i, t}$ are the individual specific (idiosyncratic) errors.

To deal with cross sectional dependency, Pesaran (2006) suggests CCE method which incorporates cross sectional averages of dependent and independent variables in panel data models as approximates of unobserved common factors. Following Pesaran (2006), the mean value of $\beta_{i}^{\prime}$ is estimated by the pooled (identical slopes) version of CCE (CCEP) estimator of Pesaran (2006). Then, we follow the suggestion of Pesaran and Tosetti (2011) and use CCEP estimator to retrieve residuals, i.e. $\hat{e}_{i, t}=y_{i, t}-\hat{\alpha}_{i}^{\prime} \mathbf{d}_{t}-\hat{\beta}_{C C E P}^{\prime} \mathbf{x}_{i, t}$ and apply Principal Component Analysis (PCA) to estimate the common factors, $\mathbf{f}_{t}$, and their loadings $\gamma_{i}^{\prime}{ }^{4}$

\footnotetext{
${ }^{3}$ We only include an intercept in $\mathbf{d}_{t}^{\prime}$.

${ }^{4}$ Note that $\hat{\beta}^{\prime}$ are simply estimated by applying OLS to $y_{i, t}=\alpha_{i}^{\prime} \mathbf{d}_{t}+\beta_{i}^{\prime} \mathbf{x}_{i, t}+\theta^{\prime} \overline{\mathbf{z}}_{t}+u_{i, t}$, where $\overline{\mathbf{z}}_{t}=\left(\bar{y}_{t}, \overline{\mathbf{x}}_{t}\right)^{\prime}$ represents the $(k+1) \times 1$ vector of cross section averages. Hence, $\hat{e}_{i, t}$, unlike $\hat{u}_{i, t}$, contain common factors captured by cross section averages.
} 
As stated by Pesaran and Tosetti (2011) these residuals are estimated consistently and an application of PCA to them will yield an estimate of common factors, i.e. $\hat{\mathbf{f}}_{t}$. Next we try to associate these estimated common factors with some possible indicators given in the empirical growth literature. The recent literature highlights the importance of institutional variables and health indicators as important determinants of economic growth. Variables for identification are selected as rule of law, political stability, voice and accountability ${ }^{5}$ and life expectancy. We check whether these indicators match with growth model's common factors, i.e., $\hat{\mathbf{f}}_{t}$. A high correlation would suggest identification of the unobserved common factors of the growth model under investigation with the institutional variables examined.

Finally we estimate factor loadings $\gamma_{i}^{\prime}$, by regressing $\hat{e}_{i, t}$ on $\hat{\mathbf{f}}_{t}$ for each $i$ separately.

\section{Empirical Findings}

We use a data set that consists of observations of 73 countries over the period of 1960-2014. We compute 5 year averages of the observations and obtain a panel data model with $N=73$ and $T=11$. The countries included in, the data sources, and the definition of the variables in the dataset are outlined in Appendix 1.

In this basic panel growth model, average (5-year averages) per capita real GDP growth rate is regressed on initial real GDP per capita level, average investment, average population growth rate plus $5 \%$ depreciation rate and average years of schooling. The results of the growth regression are given below and the sign and significance of the regressors are similar to those observed in the literature. ${ }^{6}$ As expected, the variables capturing the effects of physical and human capital; i.e. investment $\left(I N V_{i, t}\right)$ and schooling $\left(S C H L_{i, t}\right)$ generally produce a positive impact on economic growth.

\footnotetext{
${ }^{5}$ These institutional variables are considered to be the most relevant ones. World Bank definitions for these institutional variables are provided in Table A.1 in Appendix 1.

${ }^{6}$ The country specific intercepts (fixed effects) are not included to save space and the numbers in parentheses are Newey-West standard errors, see equation (74) in Pesaran (2006).
} 


$$
\hat{y}_{i, t}=\underset{(0.507)}{1.244} P O P_{i, t}+\underset{(0.022)}{0.033 S C H} L_{i, t}+\underset{(0.007)}{0.027 I N V_{i, t}}
$$

In the next stage of the analysis we apply principal component analysis (PCA) to growth residuals, $\hat{e}_{i, t}$. The first components of the residuals explains around $41 \%$ of the total variation of the growth residuals of 73 countries. We only employ the first components, $\hat{f}_{1 t}$, of growth residuals as they are able to capture the common unobserved factor estimated by the CCEP estimator.

To identify this common factor we investigate the relevant variables that may have strong correlation with $\hat{f}_{1 t}$. As mentioned in the introduction, for this purpose we use three institutional indicators: voice and accountability $\left(V A_{i, t}\right)$, political stability and absence of violence $\left(P S_{i, t}\right)$ and life expectancy $\left(L E_{i, t}\right)$. Institutional variables, in the recent literature, are argued to be the main reason behind economic differences (Acemoglu and Robinson (2010); Acemoglu et al. (2005); Acemoglu (2010)). To eliminate country specific, idiosyncratic effects and obtain cross section invariant "common components" of these indicators, we also employ PCA to those variables themselves. The first component, $P C_{1 t}^{P S}$, of $P S_{i, t}$ explains $61 \%$, whereas the first two components, $P C_{1 t}^{P S}$ and $P C_{2 t}^{P S}$ together explain $89 \%$ of the total variation. Similarly $87 \%$ of the total variation in $V A_{i, t}$ can be captured by the first two components, i.e., $P C_{1 t}^{V A}$ and $P C_{2 t}^{V A}$. On the other hand, the first component of $P C_{1 t}^{L E}$ explains $86 \%$ of the total variation in $L E_{i, t}$.

Table 1: Correlation Matrix

\begin{tabular}{|c|c|c|c|c|c|}
\hline & $P C_{1}^{P S}$ & $P C_{2}^{P S}$ & $P C_{1}^{V A}$ & $P C_{2}^{V A}$ & $P C_{1}^{L E}$ \\
\hline$\hat{f}_{1}$ & 0.883 & 0.289 & 0.880 & 0.116 & -0.904 \\
\hline $\bar{y}$ & 0.021 & 0.992 & 0.103 & 0.987 & -0.416 \\
\hline$P \bar{O} P$ & 0.867 & 0.177 & 0.904 & 0.205 & -0.942 \\
\hline$\overline{S C H} L$ & -0.988 & 0.079 & -0.985 & 0.131 & 0.994 \\
\hline$I \bar{N} V$ & -0.800 & 0.408 & -0.739 & 0.569 & 0.674 \\
\hline
\end{tabular}

We now check the correlation coefficients between common factors of growth residual and those of the institutional indicators and $L E$. The results are illustrated in Table 1. The correlation matrices reflect very high (above $88 \%$ in absolute 
value) correlation coefficients for all common factors in the first component, i.e., $P C_{1 t}^{P S}, P C_{1 t}^{V A}$ and $P C_{1 t}^{L E}$. Hence, we can argue that common factors obtained from institutional indicators and $L E$ identify the unobserved common factor(s) in our basic panel growth model. The partial correlation between $P C_{1 t}^{P S}$ and $P C_{1 t}^{V A}$ is very high (99.5\%) as these governance indicators measure the same information of institutional quality indicating that one can choose any of the two. ${ }^{7}$

The analysis is also checked for potential weakly exogenous regressors using Chudik and Pesaran (2015), an extension to the CCE model of Pesaran (2006) by including lags of cross section averages. The regression model and the correlation matrix using Chudik and Pesaran (2015) are given in Appendix 2. The model including lagged dependent variable is also checked. The results confirm the strong significance of investment (given in Table A.2.1), and also the high correlation between common factors of growth residuals and institutional variables (given in Table A.2.2). However, the population growth variable is no longer robust.

We also estimate factor loadings $\gamma_{i}^{\prime}$, by regressing $\hat{e}_{i, t}$ on $\hat{f}_{1}$ for each $i$ separately and we report these in Table A.1.2 of Appendix 1 to conserve space. The results highlight the positive impact of the unobserved factors related with institutional factors for all developed countries (a total of 17), whereas for some developing or least developed economies the unobserved common factors turn out ot be insignificant. ${ }^{8}$

Our findings suggest that retrieving common factors by employing PCA to the residuals obtained from CCE estimators points to a possible observational equivalence between these unobserved common factors and institutional indicators. Even though, some of the standard growth determinants (such as population growth) may not be robust to different specifications, we still find that the correlations

\footnotetext{
${ }^{7}$ Table 1 also presents the correlations between common factors of institutional variables as well as LE, and the cross sectional averages $\left(\bar{y}, P \bar{O} P, S C H L, I \bar{N} V\right.$ or $\overline{\mathbf{z}}_{t}$ in general terms see footnote 4 above). Cross-sectional averages, like the growth residuals, are also supposed to be (presumably less efficient) estimators of the common factors. As can be seen in the table the first principal components and the cross sectional averages are also highly correlated as expected, since these averages capture similar common institutional features as the common factors. We thank an anonymous referee for this suggestion.

${ }^{8}$ It is worth noting that the inferences in Table A.1.2 are subject to a generated regressor problem as both $\hat{e}_{i, t}$ and $\hat{f}_{1}$ are both subject to estimation error. Even though this source of error is not important for $\hat{e}_{i, t}$ as it is the dependent variable, it is certainly a problem for $\hat{f}_{1}$. Hence the results in Table A.1.2 should be viewed with caution.
} 
between common factors obtained from a typical growth model and institutional indicators plus LE variables are observed to be very high. This suggests that the common factors approximated by cross sectional averages are likely identified by these institutional variables (plus life expectancy). From an econometric specification point of view, our findings support Barro (2013) in the claim that institutions are among the most important determinants of country differences in long run economic growth and living standards. 


\section{References}

Acemoglu, D. (2010). Growth and institutions. In Economic Growth, pp. 107-115. Springer.

Acemoglu, D., S. Johnson, and J. A. Robinson (2005). Institutions as a fundamental cause of long-run growth. Handbook of economic growth 1, 385-472.

Acemoglu, D. and J. Robinson (2010). The role of institutions in growth and development. World Bank Publications.

Aisen, A. and F. J. Veiga (2013). How does political instability affect economic growth? European Journal of Political Economy 29, 151-167.

An, C.-B. and S.-H. Jeon (2006). Demographic change and economic growth: An inverted-u shape relationship. Economics Letters 92(3), 447-454.

Barro, R. J. (1996). Determinants of economic growth: a cross-country empirical study. Technical report, National Bureau of Economic Research.

Barro, R. J. (2013). Democracy, law and order, and economic growth. Bryan Riley, B. and Miller, T.(eds).

Barro, R. J. and X. Sala-i Martin (1995). Economic growth, 1995. McGrawHill, New York.

Bassanini, A. and S. Scarpetta (2001). Does human capital matter for growth in oecd countries?: Evidence from pooled mean-group estimates. OECD Economics Department Working Papers, No. 282, OECD Publishing, Paris. http://dx.doi.org/10.1787/424300244276.

Chudik, A. and M. H. Pesaran (2015). Common correlated effects estimation of heterogeneous dynamic panel data models with weakly exogenous regressors. Journal of Econometrics 188(2), 393-420.

Dawson, J. W. (1998). Institutions, investment, and growth: New cross-country and panel data evidence. Economic inquiry 36(4), 603-619. 
De Hoyos, R. E. and V. Sarafidis (2006). Testing for cross-sectional dependence in panel-data models. Stata Journal 6(4), 482-496.

Easterly, W., J. Ritzen, and M. Woolcock (2006). Social cohesion, institutions, and growth. Economics 85 Politics 18(2), 103-120.

Esfahani, H. S. and M. T. Ramirez (2003). Institutions, infrastructure, and economic growth. Journal of development Economics 70(2), 443-477.

Islam, N. (1995). Growth empirics: a panel data approach. The Quarterly Journal of Economics 110(4), 1127-1170.

Kaufmann, D., A. Kraay, and M. Mastruzzi (2011). The worldwide governance indicators: methodology and analytical issues. Hague Journal on the Rule of Law 3, 220-246.

Kelley, A. C. and R. M. Schmidt (1995). Aggregate population and economic growth correlations: the role of the components of demographic change. Demography 32(4), 543-555.

Kunze, L. (2014). Life expectancy and economic growth. Journal of Macroeconomics 39, 54-65.

Lorentzen, P., J. McMillan, and R. Wacziarg (2008). Death and development. Journal of Economic Growth 13(2), 81-124.

Mankiw, N. G., D. Romer, and D. N. Weil (1992). A contribution to the empirics of economic growth. The Quarterly Journal of Economics 107(2), 407-437.

Nawaz, S. (2015). Growth effects of institutions: A disaggregated analysis. Economic Modelling 45, 118-126.

Pesaran, M. H. (2006). Estimation and inference in large heterogeneous panels with a multifactor error structure. Econometrica 74 (4), 967-1012.

Pesaran, M. H. and E. Tosetti (2011). Large panels with common factors and spatial correlation. Journal of Econometrics 161(2), 182-202. 
Phillips, P. C. and D. Sul (2003). Dynamic panel estimation and homogeneity testing under cross section dependence. The Econometrics Journal 6(1), 217259.

Sarafidis, V. and D. Robertson (2009). On the impact of error cross-sectional dependence in short dynamic panel estimation. The Econometrics Journal 12(1), $62-81$.

Solow, R. M. (1956). A contribution to the theory of economic growth. The Quarterly Journal of Economics 70(1), 65-94. 


\section{Appendix 1: List and definition of variables}

Our investigation of growth regression uses 73 countries from 1960-2014. The data are used as five-year intervals (averages) for a long run perspective. The dataset obtained from Penn Word Tables (PWT) are averaged for 2010 and 2011 as for the last period (due to the absence of data after 2011 for a high number of countries) whereas the World Bank (WB) datasets are averaged for the 2010-2014. GDP variables have constant prices in 2005. A table of variables with their definitions is given below.

Table A.1. 1: Definition of Variables

\begin{tabular}{lll} 
Abbreviations & Definitions & Source \\
\hline$y$ & Average real GDP per capita Growth Rate & WB \\
INV & Logarithm of Average Investment (Gross capital formation (\% of GDP)) & PWT \\
POP & Average Population Growth Rate $+5 \%$ depreciation rate & WB \\
SCHL & Logarithm of Average Years of Schooling & PWT \\
VA & Voice and Accountability & WB \\
PS & Political Stability and Absence of Violence & WB \\
LE & Life Expectancy & WB \\
\hline \hline
\end{tabular}

Note: The dataset including 73 countries:Argentina, Australia, Austria, Burundi, Belgium, Benin, Bangladesh, Bolivia, Brazil, Botswana, Central, African, Republic, Canada, Chile, China,, People's, Republic, of, Cte, d'Ivoire, Cameroon, Congo, Colombia, Costa, Rica, Denmark, Dominican, Republic, Ecuador, Spain, Finland, Fiji, France, Gabon, United, Kingdom, Ghana, Greece, Guatemala, Honduras, Indonesia, India, Iran, (Islamic, Republic, of), Iceland, Israel, Italy, Japan, Kenya, Republic, of, Korea, Liberia, Lesotho, Luxembourg, Mexico, Mauritania, Malawi, Malaysia, Niger, Netherlands, Norway, Nepal, Pakistan, Panama, Peru, Philippines, Portugal, Paraguay, Rwanda, Senegal, Singapore, Sierra, Leone, Sweden, Togo, Thailand, Trinidad, and, Tobago, Turkey, Uruguay, United, States, Venezuela, South, Africa, Zambia, Zimbabwe. World Bank definitions (Kaufman et al., 2010) of VA, PS and RL are as follows. Voice and Accountability (VA): "capturing perceptions of the extent to which a country's citizens are able to participate in selecting their government, as well as freedom of expression, freedom of association, and a free media". Political Stability and Absence of Violence/Terrorism (PS): "capturing perceptions of the likelihood that the government will be festabilized or overthrown by unond 
Table A.1. 2: Estimation Results of Loadings

\begin{tabular}{|c|c|c|c|c|c|}
\hline Country & $\hat{f}_{1}$ & Std. Errors & Country & $\hat{f}_{1}$ & Std. Errors \\
\hline Argentina & 0.158 & $(0.149)$ & Israel & $0.243^{*}$ & $(0.063)$ \\
\hline Australia & $0.117^{*}$ & $(0.051)$ & Italy & $0.464^{*}$ & $(0.088)$ \\
\hline Austria & $0.464^{*}$ & $(0.043)$ & Japan & $0.465^{*}$ & $(0.127)$ \\
\hline Burundi & $0.481^{*}$ & $(0.098)$ & Kenya & $0.355^{*}$ & $(0.071)$ \\
\hline Belgium & $0.394^{*}$ & $(0.059)$ & Korea & $0.354^{*}$ & $(0.124)$ \\
\hline Benin & $0.388^{*}$ & $(0.076)$ & Liberia & 0.432 & $(0.580)$ \\
\hline Bangladesh & $0.213^{*}$ & $(0.089)$ & Lesotho & $0.524^{*}$ & $(0.154)$ \\
\hline Bolivia & $0.224^{*}$ & $(0.089)$ & Luxembourg & $0.298^{*}$ & $(0.114)$ \\
\hline Brazil & $0.327^{*}$ & $(0.103)$ & Mexico & $0.299^{*}$ & $(0.061)$ \\
\hline Botswana & $0.641^{*}$ & $(0.182)$ & Mauritania & $0.335^{*}$ & $(0.115)$ \\
\hline Central African Republic & 0.045 & $(0.138)$ & Malawi & 0.277 & $(0.166)$ \\
\hline Canada & $0.267^{*}$ & $(0.042)$ & Malaysia & $0.323^{*}$ & $(0.099)$ \\
\hline Chile & 0.094 & $(0.097)$ & Niger & 0.158 & $(0.168)$ \\
\hline China & $-0.349^{*}$ & $(0.093)$ & Netherlands & $0.220^{*}$ & $(0.041)$ \\
\hline Cote d'Ivoire & 0.306 & $(0.203)$ & Norway & $0.232^{*}$ & $(0.09)$ \\
\hline Cameroon & 0.24 & $(0.175)$ & Nepal & $0.357^{*}$ & $(0.062)$ \\
\hline Congo & 0.223 & $(0.226)$ & Pakistan & $0.229^{*}$ & $(0.065)$ \\
\hline Colombia & 0.055 & $(0.075)$ & Panama & 0.111 & $(0.152)$ \\
\hline Costa Rica & 0.214 & $(0.111)$ & Peru & $0.236^{*}$ & $(0.114)$ \\
\hline Denmark & $0.213^{*}$ & $(0.065$ & Philippines & 0.112 & $(0.107)$ \\
\hline Dominican Republic & 0.166 & $(0.136)$ & Portugal & $0.712^{*}$ & $(0.108)$ \\
\hline Ecuador & $0.187^{*}$ & $(0.096)$ & Paraguay & $0.360^{*}$ & $(0.122)$ \\
\hline Spain & $0.698^{*}$ & $(0.118)$ & Rwanda & 0.151 & $(0.202)$ \\
\hline Finland & $0.321^{*}$ & $(0.092)$ & Senegal & $0.246^{*}$ & $(0.095)$ \\
\hline Fiji & 0.183 & $(0.119)$ & Singapore & $0.378^{*}$ & $(0.168)$ \\
\hline France & $0.429^{*}$ & $(0.06$ & Sierra Leone & $0.441^{*}$ & $(0.108)$ \\
\hline Gabon & $0.975^{*}$ & $(0.195$ & Sweden & $0.289^{*}$ & $(0.076)$ \\
\hline United Kingdom & $0.168^{*}$ & $(0.072$ & Togo & $0.571^{*}$ & $(0.166)$ \\
\hline Ghana & 0.007 & $(0.131$ & Thailand & -0.017 & $(0.124)$ \\
\hline Greece & $0.579^{*}$ & $(0.102)$ & Trinidad and Tobago & 0.262 & $(0.224)$ \\
\hline Guatemala & $0.241^{*}$ & $(0.08)$ & Turkey & $0.133^{*}$ & $(0.054)$ \\
\hline Honduras & $0.211^{*}$ & $(0.085)$ & Uruguay & $0.078^{*}$ & $(0.159)$ \\
\hline Indonesia & 0.105 & $(0.096)$ & United States & $0.261^{*}$ & $(0.039)$ \\
\hline India & -0.118 & $(0.068)$ & Venezuela & -0.032 & $(0.144)$ \\
\hline Iran & $0.773^{*}$ & $(0.276)$ & South Africa & $0.259^{*}$ & $(0.080)$ \\
\hline \multirow[t]{2}{*}{ Iceland } & $0.286^{*}$ & $(0.101)$ & Zambia & 0.171 & $(0.116)$ \\
\hline & & & Zimbabwe & 0.258 & $(0.243)$ \\
\hline
\end{tabular}

Note: Standard errors are given in paranthesis. $(*)$ indicate significance at $5 \%$. 


\section{Appendix 2: Controlling for weak exogeneity}

Table A.2. 1: Chudik and Pesaran (2015) estimation results (dependent variable is $y_{i, t}$ )

\begin{tabular}{ccccc} 
& $y_{i, t-1}$ & $P O P_{i, t}$ & $S C H L_{i, t}$ & $I N V_{i, t}$ \\
\hline \multirow{2}{*}{$(1)$} & 0.660 & 0.260 & $0.068^{*}$ \\
& & $(1.126)$ & $(0.258)$ & $(0.020)$ \\
\hline \multirow{2}{*}{$(2)$} & $-0.917^{*}$ & -0.136 & 0.067 & $0.024^{*}$ \\
& $(0.068)$ & $(0.601)$ & $(0.138)$ & $(0.011)$ \\
\hline
\end{tabular}

Table A.2. 2: Correlation Matrix for Chudik and Pesaran (2015) estimators

\begin{tabular}{ccccc} 
& & $P C_{1}^{P S}$ & $P C_{1}^{V A}$ & $P C_{1}^{L E}$ \\
\hline & $\hat{f}_{1}$ & 0.997 & 0.994 & -0.996 \\
& $\bar{y}$ & 0.021 & 0.103 & -0.416 \\
(1) & $P \bar{O} P$ & 0.867 & 0.904 & -0.942 \\
& $S C H L$ & -0.988 & -0.985 & 0.994 \\
& $I \bar{N} V$ & -0.800 & -0.739 & 0.674 \\
\hline & $\hat{f}_{1}$ & 0.941 & 0.905 & -0.950 \\
& $\bar{y}$ & 0.021 & 0.103 & -0.323 \\
(2) & $P \bar{O} P$ & 0.867 & 0.904 & -0.942 \\
& $S C H L$ & -0.988 & -0.985 & 0.994 \\
& $I \bar{N} V$ & -0.800 & -0.739 & 0.528 \\
\hline
\end{tabular}

Note: (1) and (2) denote common factors of the residu-

als obtained from Chudik and Pesaran (2015) estimators

excluding and including lagged dependent, successively. 